\title{
HISTÓRIA E STIMMUNG A PARTIR DE WALTER BENJAMIN: SOBRE ALGUMAS POSSIBILIDADES ÉTICO-POLÍTICAS DA HISTORIOGRAFIA
}

\author{
Marcelo de Mello Rangel
}

\begin{abstract}
RESUMO
Tematizaremos as teses "Sobre o conceito de história" de Walter Benjamin, especialmente as teses IV, VI e VII, com o objetivo de compreender e descrever a crítica que Benjamin faz a certa leitura sedimentada de Hegel e de Marx, e isto para que possamos, num segundo momento, discutir o problema do Stimmung (clima, atmosfera, tonalidade afetiva) em especial a partir da atividade que é a da historiografia. Ao fim, nosso objetivo é o de descrever a atividade historiográfica a partir de Walter Benjamin como sendo um âmbito adequado à produção de atmosferas ou de economias sentimentais próprias a reorganização da história ou da realidade (Wirklichkeit).
\end{abstract}

Palavras-chave: Walter Benjamin; Historiografia; Stimmung; Giro ético-político

\section{HISTORY AND STIMMUNG FROM WALTER BENJAMIN: ON SOME ETHICAL-POLITICAL POSSIBILITIES OF HISTORIOGRAPHY}

\begin{abstract}
We will thematize the thesis "Über den Begriff der Geschichte" of Walter Benjamin, especially the thesis IV, VI and VII, with the aim of understanding and describing Benjamin's critique of a certain settled reading of Hegel and Marx, and this, in a second moment, with the objective to discuss the problem of Stimmung (climate, atmosphere, affective tonality) especially from the activity that is the historiography. Finally, our purpose is to describe the historiography from Walter Benjamin as a suitable scope for the production of atmospheres or sentimental economies proper to the reorganization of history or reality (Wirklichkeit).
\end{abstract}

Key words: Walter Benjamin; Historiography; Stimmung; Ethical-political turn 
A Tese IV, à qual nos dedicaremos inicialmente, começa com esta breve citação de Hegel: "Buscai, primeiro, o de que comer e vestir, e o reino de Deus vos advirá por si" (apud BENJAMIN, tese IV, 58)'.

Antes ainda de uma análise mais detida, cabe anotar o que significa uma citação para Benjamin, ou ainda, o que poderíamos chamar de uma teoria ou mesmo de uma política da citação benjaminiana. Para o filósofo alemão, a citação possui pelo menos duas funções, a saber: 1- a de mostrar possibilidades de leitura obscurecidas, e 2- a de questionar leituras e usos possíveis de determinados autores no interior desta ou daquela tradição ou fortuna crítica, reconduzindo, assim, certo pensamento ao seu horizonte ou historicidade própria ${ }^{2}$. Aliás, este seria o próprio sentido da crítica a partir de Benjamin, o de retematizar insistentemente versões finais constituídas a partir de determinados "mundos" (conjunto sedimentado de significados e sentidos) ou contextos históricos específicos ${ }^{3}$.

Pois bem, é justo isto, esta crítica e recondução fenomenológica, digamos assim, que Benjamin realiza através da citação de Hegel. Benjamin faz aparecer um Hegel que não é comum à tradição marxiana (ou que pelo menos não era à sua época). Um Hegel que apontaria para a compreensão de que o que haveria de mais fundamental e que precisaria orientar todo e qualquer pensamento e ação encurtando, inclusive, o tempo dedicado ao pensamento, seria a igualização do que é fundamental a toda e qualquer existência, o "de

\footnotetext{
${ }^{1}$ Utilizamos a tradução das Teses feita por Jeanne-Marie Gagnebin e por Marcos Lutz Müller, publicada na íntegra por Michel Löwy em seu livro "Walter Benjamin: aviso de incêndio. Uma leitura das teses 'Sobre o conceito de história'. Explicitamos, ainda, que a noção de Stimmung não é utilizada diretamente por Benjamin, se tratando, portanto, de uma categoria analítica.

${ }^{2}$ É isto que também está em questão quando Benjamin escreve que: "Todo aquele que, até hoje, obteve a vitória, marcha junto no cortejo de triunfo que conduz os dominantes de hoje [a marcharem] por cima dos que, hoje, jazem por terra. A presa, como sempre de costume, é conduzida no cortejo triunfante. Chamam-na bens culturais. Eles terão de contar, no materialismo histórico, com um observador distanciado, pois o que ele, com seu olhar, abarca como bens culturais atesta, sem exceção, uma proveniência que ele não pode considerar sem horror. Sua existência não se deve somente ao esforço dos grandes gênios, seus criadores, mas, também, à corvéia sem nome de seus contemporâneos. Nunca há um documento da cultura que não seja, ao mesmo tempo, um documento da barbárie. E, assim como ele não está livre da barbárie, também não está do processo de sua transmissão, transmissão na qual ele passou de um vencedor a outro. Por isso, o materialismo histórico, na medida do possível, se afasta desta transmissão. Ele considera como sua tarefa escovar a história a contrapelo" (BENJAMIN, tese VII, p. 70). Ver, também, RANGEL, 2015, 70-73.

${ }^{3}$ Sobre o problema da crítica em Walter Benjamin, ver CASTRO, 2011, especialmente 0 capítulo primeiro.
}

Professor do Departamento de História e do Programa de Pós-Graduação em História da Universidade Federal de Ouro Preto (UFOP). Brasileiro, residente em Ouro Preto - MG .E-mail: mmellorangel@yahoo.com.br 
que comer e vestir", evidenciando que esta tarefa precisaria ser realizada logo de início, e isto porque ela seria a própria condição de possibilidade para a existência e para o pensamento.

Ao fim, o que temos aqui é um Hegel que apontaria para um possível protagonismo do que podemos chamar de "estrutura", das condições materiais, as quais constituiriam a condição de possibilidade para a existência e para 0 refinamento da própria atividade teórica (e das instituições), da "superestrutura". A igualização do de "que comer e vestir" aparece, assim, como uma tarefa que deveria ser realizada antes de todo o mais - antes do Estado, do direito, da religião, da Constituição e do Parlamento, da própria filosofia, de todo e qualquer prazer ou alegria.

Assim, compreendemos a citação de Hegel como parte de uma teoria ou política da citação benjaminiana, ou seja, como tematização e explicitação da riqueza ou pluralidade de um texto ou obra, evidenciando que (determinadas) interpretações provocam o obscurecimento de parte desta riqueza, o que no caso de Hegel significa percebê-lo como uma espécie de "idealista" que compreenderia que toda e qualquer transformação da história ou da realidade (Wirklichkeit) teria sua origem ou poderia (deveria) ser acompanhada e descrita, mais propriamente, a partir de um âmbito teórico refinado, e isto no interior de algumas instituições específicas como o Estado e a filosofia.

Mas o que é ainda mais significativo e mesmo surpreendente é que Benjamin não está propriamente de acordo com esta compreensão hegeliana, ele não acredita que o protagonismo ou aquilo mesmo que deve orientar todo e qualquer pensamento e ação, originariamente, seja o "de que comer e vestir". Em linhas gerais, e trabalharemos isto em seguida, Benjamin compreende que o mais próprio ao pensamento seria, antes de tudo, se dedicar à provocação de uma determinada economia sentimental ou atmosfera (Stimmung) específica e adequada ou favorável à assunção, posterior, da tarefa que é a da igualização das condições materiais da existência. Dizendo ainda de outra forma, para que esta tarefa que é a da igualização possa ser levada a cabo é necessário que haja ânimo suficiente, pois apenas assim seria possível, por conseguinte, insistir nesta atividade que ao fim seria árida e que tenderia à supressão. 
A "luta de classes" não começa e nem deveria começar pela igualização do "de que comer e vestir", mas sim pela provocação e assunção de determinados sentimentos, economia sentimental ou atmosfera (Stimmung) que tornaria possível, que seria a própria gênese desta atividade ou reivindicação (da igualização), a qual seria sempre violentamente negada, trata-se de uma economia sentimental determinada pelo páthos da "coragem", do "humor" e da "confiança" como acompanharemos mais adiante. Ou seja, trata-se de compreender que todo e qualquer pensamento e ação que pretenda uma transformação efetiva da realidade ou a reorganização da história a partir da igualização do "de que comer e vestir", precisaria se constituir no interior ou a partir de uma economia sentimental favorável à insistência nesta reivindicação que seria necessária e incessantemente contestada e suprimida.

É a partir desta compreensão, por exemplo, que podemos ler a tese II, na qual Benjamin explicita o caráter de "fragilidade" (schwache) da atividade que é a da tematização e reorganização da história, que aparece, neste momento, a partir da noção de "redenção" (Erlösung). Ou ainda, se trata da necessidade mesma de se retomar incessantemente esta atividade ou tarefa, "a cada geração", renovando a sua condição de possibilidade que é justo a da constituição de uma atmosfera (Stimmung) adequada ou favorável a este exercício que tende a ser negado e mesmo suprimido, e isto porque "nos foi dada, assim como a cada geração que nos procedeu, uma fraca força messiânica, à qual o passado tem pretensão" (BENJAMIN, tese II, 48).

Pois bem, a Tese IV trata então de explicitar que boa parte das tradições marxianas à sua época não teria se preocupado em provocar e constituir as condições de possibilidade ideais a todo e qualquer pensamento e ação dedicados à reorganização ou diferenciação significativa da história ou da realidade (Wirklichkeit), ou ainda, não teria se preocupado em sublinhar o papel originário do que estamos chamando aqui de atmosfera ou Stimmung. Assim, teríamos duas leituras equivocadas, a que conferiria a Hegel um descaso radical no que diz respeito às condições materiais e, em seguida, as que deixariam de perceber, no pensamento do próprio Marx, a importância do que chamamos de atmosfera (Stimmung) ou economia sentimental. Segundo Benjamin:

Professor do Departamento de História e do Programa de Pós-Graduação em História da Universidade Federal de Ouro Preto (UFOP). Brasileiro, residente em Ouro Preto - MG .E-mail: mmellorangel@yahoo.com.br 
A luta de classes, que um historiador escolado em Marx tem sempre diante dos olhos, é uma luta pelas coisas brutas e materiais, sem as quais não há coisas finas e espirituais. Apesar disso, estas últimas estão presentes na luta de classes de outra maneira que a da representação de uma presa que toca ao vencedor. Elas estão vivas nessa luta como confiança, como coragem, como humor, como astúcia, como tenacidade, e elas retroagem ao fundo longínquo do tempo. (BENJAMIN, tese IV, 58)

Segundo Benjamin, todo e qualquer pensamento "escolado" (geschult) ou orientado por Marx teria de se atentar e mesmo de se constituir a partir da compreensão de que as "coisas finas e espirituais" seriam a origem mesmo da transformação efetiva da história, neste caso, mais especificamente, a partir do esforço teórico, intelectual, dedicado à produção (producere, trazer para diante) de uma atmosfera específica adequada àquela atividade (a da igualização e rearticulação da história). Para o filósofo alemão, as "coisas finas e espirituais", ou ainda, a produção (producere) de uma economia sentimental determinada por sentimentos como a "coragem", o "humor" e a "confiança", seria a origem, o ponto de determinação mesmo dos pensamentos e ações "revolucionários", de modo que estes sentimentos não seriam algo a ser conquistado ou mesmo digno de ser experimentado a partir da igualização das condições materiais ("uma presa que toca ao vencedor"), mas sim a própria condição de possibilidade para que houvesse ao menos a possibilidade de um esforço ou empenho significativo neste sentido (o da igualização). São tais sentimentos que tornariam possível que se ponha "... incessantemente em questão cada vitória que couber aos dominantes". Trata-se, assim, de preocupar-se com uma atividade teórica dedicada à provocação de um âmbito favorável à atividade ou reivindicação que é a da igualização do "de que comer e vestir".

\section{Historiografia e Stimmung}

A historiografia no sentido benjaminiano pode ser compreendida como uma atividade dedicada à tematização de passados, e isto a partir da crítica de interpretações mais gerais ou de versões finais (o que pode ocorrer a partir da teoria da história, da história da historiografia, da história do Brasil ou da África, da história da arte ou da filosofia, por exemplo), a qual liberaria realidades ou 
historicidades específicas em relação às determinações próprias ao horizonte histórico ou "mundo" sedimentado e congelado no interior do qual esta atividade precisa se constituir. Estas realidades ou historicidades, por sua vez, teriam o poder de: 1 - "orientar" de algum modo os homens em geral no que tange ao seu posicionamento no interior do presente, 2 - evidenciar o caráter de possibilidade que é o da história, tendo em vista que a partir desta atividade a lógica própria à história poderia ser visualizada, a saber: a de ser um movimento determinado pela co-pertinência entre ser e devir, ou ainda, pela alternância entre horizontes mais sedimentados e instantes (Jetztzeit) a partir dos quais outros horizontes ou aspectos se tornariam possíveis. E, 3 - o que é mais adequado ao nosso ensaio, esta atividade historiográfica que é determinada pela crítica, acompanhada da restituição deste ou daquele tema ao horizonte que é o seu, liberando realidades ou historicidades especificas teria o poder de animar determinado presente (congelado), e isto em razão do simples caráter de diferença próprio a esta ou àquela historicidade, e/ou, também, em razão de uma espécie de participação, experimentação (fenomenologicamente constituída) de determinados "mundos" ou atividades específicas, e, mais propriamente, a partir da experimentação (co-participação) da sua economia sentimental, da "coragem", "humor" e "confiança" disponível. O que está em questão aqui é que esta atividade que seria a da historiografia se dedicaria à tematização - crítica, restituição e liberação - de determinados entes e performances mais especificamente empenhados na "negação" (Gegenständlichkeit) e reconstituição de seu próprio "mundo". De modo que, neste sentido, a atividade historiográfica descrita por Benjamin não se dedicaria mais propriamente ao conhecimento de todo e qualquer passado, mas à participação e continuação de determinados entes e performances críticas dedicadas, em algum momento, à disputa pela diferenciação e reorganização da história. Estes homens e mulheres seriam capazes de animar, através da historiografia, as gerações posteriores, ou, para usar termos próprios ao Nietzsche da "Il Consideração Intempestiva...", de se dedicar, uma vez mais, 
ao acolhimento do devir e ao trabalho (à elaboração) que é o da constituição de novas delimitações em seu interior ${ }^{4}$.

Se, por um lado, a atividade historiográfica aparece ou mesmo também pode ser compreendida como um espaço adequado à constituição de determinada atmosfera ou Stimmung própria à insistência infinita nisto que seria a igualização do "de que comer e vestir", haveria um passo ainda anterior que também caberia a ela, o da suspensão (sempre frágil) de uma economia sentimental específica que seria própria à história em geral, mas que teria se congelado no interior da modernidade, a saber, a da "apatia" ou do "conformismo", pois "em cada época é preciso tentar arrancar a transmissão da tradição ao conformismo que está na iminência de subjugá-la" (BENJAMIN, tese $\mathrm{VI}, 65)^{5}$.

O que está em questão aqui é que a modernidade teria se constituído como um espaço no interior do qual o caráter de possibilidade da história teria sido radicalmente obscurecido, e os homens em geral esquecido da importância própria ao pensamento e à ação, de modo que, ao fim, o que teríamos seria um "mundo" e uma atmosfera (a do "conformismo") congelados, no qual os comportamentos teóricos e práticos estariam sendo incessantemente determinados por um conjunto específico de orientações e sentimentos de modo a produzir a repetição de um mesmo aspecto ou "hierarquia" no sentido nietzschiano.

Neste caso e como mencionamos mais acima, a historiografia apareceria como uma atividade a partir da qual esta reiteração poderia ser questionada e

\footnotetext{
${ }^{4}$ Neste sentido, podemos aproximar a perspectiva benjaminiana de parte das compreensões de Nietzsche sobre a história e a historiografia explicitadas em sua "II Consideração Intempestiva...", especialmente, neste caso, no que diz respeito à atividade ou ao comportamento historiográfico descrito a partir da figura que é a "história monumental". Cf. NIETZSCHE, 2003. Ver, também, RANGEL, 2010.

Ressaltamos, ainda, que a "II Consideração Intempestiva..." foi um texto fundamental ao Benjamin das Teses, que inicia a tese XII com a seguinte citação de Nietzsche: "Precisamos da história, mas precisamos dela de outra maneira que o mimado caminhante ocioso no jardim do saber". (apud BENJAMIN, tese XII, 108)

${ }^{5}$ Compreendemos que esta atmosfera (Stimmung) que é a do "conformismo" seria própria à história em geral, pois ela se constituiria com base na necessidade histórica que é a da reconstituição e sedimentação de horizontes específicos, e isto a partir do obscurecimento do caráter de possibilidade ou de diferenciação que é o da história. No entanto, o que podemos descrever a partir de Benjamin é que a modernidade, especialmente a partir da "ideologia" do "progresso", teria radicalizado este obscurecimento e, por conseguinte, tornado possível o congelamento desta atmosfera.

Professor do Departamento de História e do Programa de Pós-Graduação em História da Universidade Federal de Ouro Preto (UFOP). Brasileiro, residente em Ouro Preto - MG .E-mail: mmellorangel@yahoo.com.br
} 
mesmo suspensa, e isto a partir da reconstituição e liberação de outros "mundos" ou historicidades específicas. De forma ainda mais clara, a modernidade teria se constituído num "mundo" congelado, determinado por um conjunto específico de significados e de sentidos - por exemplo, progresso, Estado, democracia e direito-os quais teriam se constituído como condição de possibilidade de todo e qualquer comportamento teórico ou prático, provocando, assim, o que podemos chamar a partir de Benjamin de uma atmosfera de "conformismo".

A atividade historiográfica precisaria, deste modo, se constituir como uma atividade própria à suspensão desta atmosfera (do "conformismo") para que fosse possível a própria constituição de uma economia sentimental favorável a comportamentos teóricos e práticos comprometidos com a igualização do "de que comer e vestir", ou ainda, adequados à atualização do caráter de possibilidade que seria o da história, à sua reorganização. Trata-se, como anotamos mais acima, de se ser crítico em relação às versões finais ou "interpretações" constituídas em torno de determinados entes e performances específicos e de uma recondução deles ao seu horizonte, para que a partir da liberação de novas historicidades possa haver o abalo ou mesmo a suspensão desta atmosfera (Stimmung) que é a do "conformismo".

Neste sentido, e isto nos parece fundamental, não haveria um método ou caminho específico que assegurasse mais propriamente a suspensão deste ou daquele historiador em relação ao "mundo" (congelado) que é o seu, e, por conseguinte, a experimentação ou "audição" deste ou daquele ente obscurecido por versões finais. Infelizmente não teremos tempo aqui para tematizar este problema com o cuidado que gostaríamos, mas cabe ao menos explicitar que muito mais ou muito menos do que métodos específicos que seriam próprios ou que assegurariam esta possibilidade de suspensão em relação ao seu próprio "mundo" e, por conseguinte, a negação desta atmosfera (Stimmung) que é a do "conformismo", o que parece estar em questão é o que podemos chamar muito rapidamente de uma sensibilidade ou de uma intuição fenomenológica, uma espécie de desconfiança ou de "lassidão" ou ainda de "tédio" - para usar uma noção que Benjamin mobiliza em seu "O narrador..." em relação às determinações próprias a este "mundo" congelado e também Universidade Federal de Ouro Preto (UFOP). Brasileiro, residente em Ouro Preto - MG .E-mail: mmellorangel@yahoo.com.br 
certo cuidado ou mesmo responsabilidade de base (gratuitos) no que diz respeito ao que poderíamos chamar de acolhimento de "diferenças" (de tudo o que não é mais propriamente familiar) que emergem "secretamente" ou misteriosamente (com base num tempo ou lógica específica) a partir de determinados passados ${ }^{6}$.

Ou ainda, se trata de uma preocupação e cuidado de base em relação a tudo o que não se confunde comigo e que se remete a mim a partir de passados específicos, num "determinado instante", e que solicita um comprometimento (empatia) gratuito (BENJAMIN, tese $\mathrm{V}, 62$ ). De modo que seria necessário que aquele que se dedica a uma atividade historiográfica orientada pelas compreensões benjaminianas se comprometesse, antes de mais nada, com a "diferença", com tudo o que não se confunde com isto que ele é ou com o seu próprio "mundo", para que a partir de então possa se relacionar intimamente com estes ou aqueles passados específicos, possa tematizá-los (justificando-os) e liberá-los. É justo esta atividade historiográfica fundada numa preocupação e cuidado gratuitos em relação ao passado que torna possível a suspensão da atmosfera (Stimmung) do "conformismo" e a constituição ou produção (provocação) da economia sentimental adequada ou favorável à atividade de igualização do "de que comer e vestir" e, por conseguinte, favorável à possibilidade de reorganização da história ou da realidade (Wirklichkeit).

É justo a partir deste horizonte que Benjamin escreve a tese VII, na qual critica Fustel de Coulanges e o que chama de historicismo. Neste momento,

\footnotetext{
${ }^{6}$ Sobre esta relação e possível articulação "secreta" que seria constituída a partir de uma intimidade radical entre determinados passados e presentes, podemos ler: 1- "O passado leva consigo um índice secreto pelo qual ele é remetido à redenção. Não nos afaga, pois, levemente um sopro de ar que envolveu os que nos precederam? Não ressoa nas vozes a que damos ouvido um eco das que estão, agora, caladas? (...) Se assim é, um encontro secreto está então marcado entre as gerações passadas e a nossa". (BENJAMIN, tese II, 48). E, 2- "A verdadeira imagem do passado passa célere e furtiva. É somente como imagem que lampeja justamente no instante de sua recognoscibilidade, para nunca mais ser capturado (...) pois é uma imagem irrestituível do passado que ameaça desaparecer com cada presente que não se reconhece como nela visado". (BENJAMIN, tese V, 62). Neste sentido ver Rangel, 2015, 47-50, e, no que tange a um problema similar a partir de Heidegger, ver FOGEL, RUIN e SCHUBACK, 1996.
} 
Benjamin retoma uma passagem ou uma espécie de procedimento ou protocolo que seria próprio à historiografia de Coulanges e, no limite, disto que ele classifica como historicismo, o de "banir de sua cabeça tudo o que saiba do curso ulterior da história" (BENJAMIN, tese VII, 70). Para o filósofo alemão este método, comprometido com a negação do que seria o "anacronismo", seria o caminho mesmo a partir do qual a atividade historiográfica intensificaria ou repetiria este ou aquele "mundo" específico e congelado. O que está em questão aqui é que uma suspensão como esta no que diz respeito a todo "conhecimento" imediato (ou participação num sentido mais fenomenológico) em relação a determinado ente ou performance e todo o mais que tenha se desdobrado a partir dele, provocaria o exato oposto do que Benjamin pretende. Provocaria a própria quebra da intimidade e empatia em relação a determinados passados e, por conseguinte, a sua reconstituição gnosiológica (ou produção de versões finais) determinada pelas orientações próprias ao "mundo" do historiador, neste caso Coulanges.

Ainda segundo Benjamin, esta posição teórica de Coulanges teria origem ou bem numa identificação objetiva com este "mundo" congelado ou bem numa identificação mais "inconsciente" que se constituiria a partir de uma tendência própria à lógica da história. Como escreve: a origem desta posição "é a indolência do coração, a acedia, que hesita em apoderar-se da imagem histórica autêntica que lampeja fugaz" (BENJAMIN, tese VII, 70), ou ainda, a ausência de responsabilidade e mesmo de amor (caritas) em relação a entes e performances específicas que apesar de todo o esforço e dedicação não foram capazes de reorganizar o seu próprio "mundo".

Esta atmosfera específica que é a do "conformismo" é constituída por um sentimento de base, a "tristeza", a qual determina todo e qualquer comportamento teórico e prático. Essa "tristeza" provocaria os homens em geral a pensar e a agir a partir e em acordo (Stimmen) com o que já vigora, ou como vimos mais acima, com o "mundo" específico (e congelado) no interior do qual nos mobilizamos (neste caso a modernidade), provocando a repetição incessante de determinado aspecto ou hierarquia. De modo que a atividade historiográfica seria, de acordo com Benjamin, um exercício a partir do qual seria possível uma suspensão, mesmo que provisória, em relação a este Professor do Departamento de História e do Programa de Pós-Graduação em História da Universidade Federal de Ouro Preto (UFOP). Brasileiro, residente em Ouro Preto - MG .E-mail: mmellorangel@yahoo.com.br 
sentimento - o da "tristeza" - e a esta atmosfera (Stimmung) - a do "conformismo", o que tornaria possível, por sua vez, a própria reorganização ou diferenciação da história a partir da tarefa que é a da igualização.

\section{REFERÊNCIAS}

ABREU, Marcelo; RANGEL, Marcelo de Mello. Memória, cultura histórica e ensino de história. História e Cultura, v. 2, n. 4, set. 2015. http://periodicos.franca.unesp.br/index.php/historiaecultura/article/view/1625

ARAUJO, Valdei Lopes de. História da historiografia como analítica da historicidade. História da Historiografia, nº 12, p. 34-44, 2013.

ARAUJO, Valdei Lopes de; RANGEL, Marcelo de Mello. Teoria e história da historiografia: do giro linguístico ao giro ético-político. História da Historiografia, $\quad \mathrm{n}^{\circ} \quad 17, \quad 2015$. https://www.historiadahistoriografia.com.br/revista/article/view/917

BENJAMIN, Walter. Sobre o conceito de história. In.: LÖWY, Michael. Walter Benjamin: aviso de incêndio. Uma leitura das teses "Sobre o conceito de história". Trad. Jeanne Marie Gagnebin e Marcos Lutz Müller. São Paulo: Boitempo Editorial, 2005.

. Über den Begriff der Geschichte. Gesammelte Schriften, t. 1 (2), p. 691-704. Frankfurt am Main: Suhrkamp, 1974.

CALLADO, Tereza de Castro. A experiência da origem. Fortaleza: EdUECE, 2006.

CASTRO, Claudia. A alquimia da crítica. Benjamin e As afinidades eletivas de Goethe. Rio de Janeiro: Paz e Terra, 2011.

DERRIDA, Jacques. Força de Lei. O 'Fundamento místico da autoridade'. São Paulo: Martins Fontes, 2010.

FOGEL, Gilvan; RUIN, Hans; SCHUBACK, Márcia Sá Cavalcante. Por uma fenomenologia do silêncio. Rio de Janeiro: Sette Letras, 1996.

FREITAS, Romero. Estilo e método da filosofia nos primeiros trabalhos de Walter Benjamin. In.: DUARTE, Rodrigo; FIGUEIREDO, Virgínia (Orgs.). Mímesis e expressão. Belo Horizonte: Editora UFMG, 2001.

. "Estranhamento ou empatia? Notas sobre o problema do conhecimento histórico em Walter Benjamin". In.: IANNINI, Gilson; GARCIA, 
Douglas; FREITAS, Romero (Orgs.). Arte e Filosofia. Antologia de textos estéticos. Rio de Janeiro: Civilização Brasileira, 2015.

GAGNEBIN, Jean-Marie. Apagar os rastros, recolher os restos. In.: SEDLMAYER, Sabrina; GUINZBURG, Jaime (Orgs.). Walter Benjamin. Rastro, aura e história. Belo Horizonte: Editora UFMG, 2012.

História e narração em Walter Benjamin. São Paulo: Perspectiva; FAPESP: Campinas, SP: Editora da Universidade Federal de Campinas, 1994.

Rio de Janeiro: Imago Ed. 1997.

Setes aulas sobre linguagem, memória e história.

GUMBRECHT, Hans Ulrich. Atmosfera, ambiência, Stimmung. Sobre um potencial oculto da literatura. Rio de Janeiro: Contraponto: Editora PUC-Rio, 2014.

als Potenzial fuer die Zukunft geblieben? (No prelo)

"Depois de 'Depois de aprender com a história', o que fazer com o passado agora?" In.:NICOLAZZI, Fernando; MOLLO, Helena Miranda; ARAUJO, Valdei Lopes de (Orgs.). Aprender com a história? O passado e o futuro de uma questão. Rio de Janeiro: FGV, 2011.

São Paulo, 1999.

. Em 1926. Vivendo no limite do tempo. Rio de Janeiro;

Produção de presença. $O$ que o sentido não consegue transmitir. Rio de Janeiro: Contraponto: Ed. PUC-RIO, 2010.

GUMBRECHT, Hans Ulrich; MARRINAN, Michael. Mapping Benjamin. The work of art in the digital age. Stanford: Stanford University Press, 2003.

HADDOCK-LOBO, Rafael. "Walter Benjamin e Michel Foucault: a importância ética do deslocamento para uma Outra História". Revista Comum, Rio de Janeiro, v. 9, n. 22, pp. 56-75, jan.-jun, 2004.

HEIDEGGER, Martin. Contribuições à filosofia. Do acontecimentto apropriativo. Rio de Janeiro: Viaverita Editora, 2015.

Ser e Tempo. Petrópolis: Vozes; Bragança Paulista: Editora Universitária São Francisco, 2008.

Sein und Zeit. Tübingen: Max Niemeyer Verlag, 2006.

KONDER, Leandro. Kafka Vida e Obra. Rio de Janeiro: Jose Álvaro Editor, 1967. 
. Walter Benjamin: O Marxismo da Melancolia. Rio de Janeiro: Civilização Brasileira, 1999.

LÖWY, Michel. Walter Benjamin: aviso de incêndio. Uma leitura das teses "Sobre o conceito de história". São Paulo: Boitempo, 2005.

MATE, Reyes. Medianoche en la historia. Comentarios a las tesis de Walter Benjamin "Sobre el concepto de historia". Madrid: Editorial Trotta, 2006.

MATOS, Olgária. Benjaminianas. Advinhas do tempo: êxtase e revolução. São Paulo: HUCITEC, 2008.

Os arcanos do inteiramente outro. A Escola de Frankfurt. A melancolia e a revolução. São Paulo: Editora Brasiliense, 1989.

Kant. São Paulo: Brasiliense, 1999.

O iluminismo visionário: Benjamin, leitor de Descartes e "Pórticos e passagens: Walter Benjamin - contratempo e história". In.: MACHADO, Carlos Eduardo Jordão; MACHADO Jr. Rubens; VEDDA, Miguel (orgs.). Walter Benjamin. Experiência histórica e imagens dialéticas. São Paulo: Editora Unesp. 2015.

. Walter Benjamin: pólis grega, metrópoles modernas. In.: JOBIM E SOUZA, Solange; KRAMER, Sonia (Orgs.). Política cidade educação. Itinerários de Walter Benjamin. Rio de Janeiro: Contraponto: Editora PUC-RIO, 2009.

MURUCI, Fábio; RANGEL, Marcelo de Mello Rangel. Algumas palavras sobre giro ético-político e história intelectual. Revista Ágora, Vitória, n. 21, 2015, pp. 7-14. http://periodicos.ufes.br/agora/issue/view/603/showToc

NIETZSCHE, Friedrich. Segunda Consideração Intempestiva. Da utilidade e desvantagem da história para a vida. Rio de Janeiro: Relume Dumará, 2003.

PINHO, Amon. "Da história como ciência e como forma de rememoração: Construção salvadora e destruição redentora em Walter Benjamin". In: Cadernos Benjamin, v. 1, Julho a Dezembro de 2008.

RANGEL, Marcelo de Mello. Justiça e História em Derrida e Benjamin. Sapere Aude, Belo Horizonte, v. 4, n. 7, 2013, pp. 347-359. http://periodicos.pucminas.br/index.php/SapereAude/article/view/4929 "Melancolia e história em Walter Benjamin". Revista Ensaios Filosóficos, v. XIV - $\quad$ Dezembro/2016. http://www.ensaiosfilosoficos.com.br/Artigos/Artigo14/11 RANGEL Ensaios Fil osoficos Volume XIV.pdf 
Modernidade e história a partir de Walter Benjamin e Derrida. Tese de doutorado defendida no Programa de PósGraduação em Filosofia (PPGF) da Universidade Federal do Rio de Janeiro (UFRJ), 2015.

"Sobre a utilidade e desvantagem da ciência histórica, segundo Nietzsche e Gumbrecht”. Dimensões, Universidade Federal do Espírito Santo (UFES), v. 24, 2010, pp. 208-241. http://www.periodicos.ufes.br/dimensoes/article/view/2531 